\title{
发挥互联网力量 促进高校体育课程高质量发展
}

\author{
袁雨馨 \\ 北京体育大学 \\ DOI:10.32629/er.v3i9.3226
}

\begin{abstract}
[摘 要] 在体育课程改革的进程中,传统的体育教育范式早已不能满足现今体育教育的要求。本文通过 文献分析法对在 “互联网 +” 背景下国内外体育课程发展的现状及优势进行了研究,并提出了我国高校 体育课程借助互联网发展的路径。研究认为, 互联网和体育课程融合发展有助于建立大数据, 满足学生的 个性化需要,提高学生的课堂积极性,因此,提出以下建议: (1)合理利用现代科技,推进教育信息化; (2)明 确学生成长目标, 激发学习主动化; (3) 凝聚社会多方力量, 促进课程优质化。
\end{abstract}

[关键词] 体育课程; 互联网; 发展

中图分类号: G611 文献标识码: A

\section{1 “互联网 + ” 概念的提出}

“互联网+”概念是在传统互联网 的基础上形成的新概念, 是指以互联网 为基础, 将各种资源进行有效的整合, 进 而实现资源的最大化利用, 使其效益达 到最大化。 ${ }^{[1]}$ “互联网+”这一概念在 我国最早是由于扬在 2012 年第五届移动 互联网博览会上提出的, 他认为“互联网 十”在未来将会发展成一种行业的新产 品和服务。随后马化腾在两会中呼吁大 家, 要以 “互联网 + ” 为驱动, 促进我国 经济和社会的创新发展。国务院印发的

《关于积极推进 “互联网 + ” 行动的指 导意见》也积极促进了互联网、大数据、 云计算等与现代制造业的结合。因此, “互联网+”已经成为了一种新的经济 形态, 并在生产要素配置中发挥着重要 的优化及集成作用。

\section{2 “互联网+” 背景下体育课程} 的发展现状

2.1 国外发展现状。美国对于在线课 程的研究起步较早, 早在 20 世纪末期, 美 国就尝试着建立虚拟学校 (Virtual School）。虚拟学校的课程几乎涵盖了线 下的所有课程, 其中也包括了体育课程。 由于体育课程较为特殊, 实践课堂中对 于场地的要求较为灵活, 所以虚拟学校 的课程中的体育课程被分为了线上和线 下两部分。 ${ }^{[3]}$ 线上课程包括了体育的相
关学科如心理学、生理学、解剖学等知 识, 考核以线上考核的方式进行; 而线下 课程则包括了一些运动项目如跳高、跳 远、跑步、游泳等, 学生完成相应的学习 任务之后, 由教师对其学习成果进行检 查。从1997年, 佛罗里达州就率先建立了 可供高中生进行线上学习体育课程的虚 拟学校, ${ }^{[4]}$ 随着远程教育的发展, 美国 K-12在线教育的注册人数突破 100 万人。 ${ }^{[5]}$ 越来越多的州开设了在线体育课程, 并对授课教师进行了明确的资格要求。

${ }^{[6]}$ 经过多年的发展, 美国已经建立了较 为完善的针对高中阶段的在线体育课程 体系, 并制定了《在线体育课程初始指 南》作为指导标准。

近年来, 美国学者针对业界所提出 的一些疑问做出了研究。Mcnamara等认 为学生在知识层面的学习上, 线下课程、 混合课程 (线上十线下) 和线上课程所得 收益区别不大, 但线下课程对于学生身 体肌肉的发展是不可忽略的。 ${ }^{[8]}$ Kooiman 等发现在在线课程中融入游戏教学法对 心率、视觉敏锐度和运动动机的提高均 有有效帮助。 ${ }^{[9]}$ Daum等发现, 有部分州对 于教师的资格并没有严格的规定; 在线 体育教师在制定课程内容时更倾向于参 照健身房或社区运动中心已有的设备来 进行安排, 对学生实际的需求考虑欠佳; 大多数教师所安排的课程并未达到
NASPE所要求的高中生每周的运动量 (225min/周)。 ${ }^{[10]}$ 另外, Brian等还发现, 与传统体育课程相比, 在线体育课程缺 乏学生与同伴的互动。 ${ }^{[11]}$ 由此可见, 当 前的在线体育课程还不够完备。

2. 2 国内发展现状。在信息时代里, 互联网几乎可以与所有行业相结合, 成 为了一种常见的社会现象。通过与互联 网的结合, 一些传统的行业能迅速得到 传播并被人们熟知。而大学生作为时代 的新兴力量, 在日常生活中习惯并善于 利用互联网对事物进行处理, 因而, 在高 校体育课程的改革和发展中, 应利用大 学生的这一特点。刘伟的《高校体育教 育创新理念与实践教学探究》一书中提 到了 “互联网十教育” 这一概念, 顾名思 义就是讲网络和教育进行融合, 取互联 网的精华, 去其糟粕, 在教学过程中充分 发挥互联网的优势, 打破传统教育的弊 端, 突破其局限, 提高教学质量。 ${ }^{[12]}$ 目前, “互联网 + ”与体育教育成为了时下的 研究热点。林岗 ${ }^{[13]}$ 分析了当前成人体育 教育场域缺失的现状, 并提出相应的重 建策略。她认为, 应对当前课程目标不准 确、课程设置不合理、教学模式跟不上 和认知内驱力不足的问题, 应采取重新 整合教育资源、开展混合教学模式和运 用大数据创新成人体育教育的手段。尹 忠根 ${ }^{[14]}$ 通过结合基于 “互联网+” 的智 
能手环和体育网络管理APP平台, 对大学 生进行了大学体育课内外健康数据的一 体化教学实践研究, 研究表明, 该实践不 仅能实现对体育课程的数据化管理, 同 时也能提升学生的体质健康水平。赵彩 钰 ${ }^{[15]}$ 对我国大学武术教学在“互联网十教 育”环境下改革的优势和策略进行了分析 提出, “互联网十教育” 背景强调了大学 生在学习中的主体地位, 为武术教师提供 了丰富的学习资源, 可以通过互联网拍摄 优质视频, 建立专属于习武人的资源库, 搭建网络考核平台, 丰富考核模式。姜玉 红 ${ }^{[16]}$ 在研究高校体育教育的改革时发现, 利用互联网、移动终端和移动应用的便捷 性、便携性和广泛性, 使高校体育教育微 课化、社交化、翻转化和混合化, 能有效 促进高校体育教育的生态化演进, 实现改 革和创新。由此可见, 将体育教育合互联 网进行有机的融合能促进我国高校体育 教育的改革和发展。

\section{3 “互联网 + ”与高校体育课 程融合发展的优势}

3. 1 利用互联网构建大数据。在传统 背景下, 课程和教学内容的设置常常是 由教师通过主观经验结合教学任务来进 行安排, 这样传统的教学模式显然已经 无法适应当前社会。大数据背景要求注 重数据宏观的、整体的概念, 更强调以全 方位和多角度的眼光对数据进行处理与 分析。我国部分高校在假期中要求学生 进行 “运动打卡”, 对其训练量、训练时 间和训练内容作出要求, 促进学生在家 也能进行锻炼, 并要求学生利用电子设 备对自己的运动过程进行记录 (如图1)。 教师能借助视频对学生的训练状态和训 练中动作轨迹、速率等进行监督和控制, 学生也能通过可视的轨迹了解自己对运 动技能的掌握情况, 促进教学的反馈机 制。其次, 互联网的功能之一就是记忆功 能, 而在体育教学的过程当中, 教师不仅 需要对运动员的身体形态、机能、素质、 心理状态等进行实时的把控, 以便于迅速 作出调整, 还需要通过灵活运用互联网的 记忆和数据处理功能, 将运动数据、运动 视频、教学过程等上传到互联网更新运动 员个人的运动大数据, 并对其进行数据

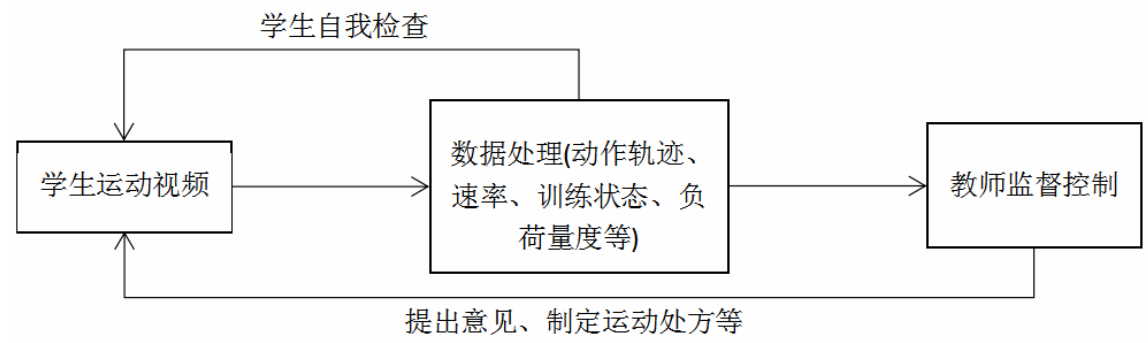

图 1 互联网数据处理与反馈机制

表 1 传统教学与互联网教学的对比

\begin{tabular}{|c|c|c|}
\hline & 传统教学 & 互联网教学 \\
\hline 教学方式 & 面对面教学 & 线上十线下教学 \\
\hline 教学内容选择 & 教师 & 学生 \\
\hline 教学内容 & 教师通过自身主观经验安排 & 学生通过自身需要和兴趣选择 \\
\hline 教学效果 & $\begin{array}{c}\text { 学生接受能力参差不齐, 深入了解 } \\
\text { 感兴趣的内容困难 }\end{array}$ & $\begin{array}{c}\text { 学生可通过自主学习弥补短板, 促进个 } \\
\text { 性化教学 }\end{array}$ \\
\hline 优势 & 部分学科的教学更加直观 & 场地、时间、学习内容灵活, 降低成本 \\
\hline
\end{tabular}

的储存、整理和分析, 以便针对学生的身 心发育、营养均衡等各方面作出进行及 时的调整, 以推动教学系统的构建。

3. 2 满足学生的个性化需要。互联网 拥有丰富的教学资源和学习资源, 这些 资源能在学校课程之后满足学生对于课 外知识的需求 (如表1)。在传统的教学模 式当中, 师生只能通过有限的课堂时间 进行面对面的授课和交流, 而所能交流 的内容常常由教师来决定, 大多与课堂 上所学内容相关, 很难涉及到课外知识, 这样导致学生所能接触的知识面有一定 的局限, 并对于自己感兴趣的部分无法 进行深入了解。另外在高校当中, 一门课 通常有几百名学生但只有一位授课老师, 一对一的答疑显然不太现实, 导致无法 根据学生的学习情况给出老师的建议和 单独的辅导。在我国高校教学改革的背 景下, 正在大力发展在线教育, 目前网络 课程已经有了慕课、微课、翻转课堂等 多种形式, 学生能在课下时间根据自身 需要和兴趣爱好选择学习课程, 制定学 习计划, 查漏补缺, 发展爱好, 学生自主 学习跨学科知识不仅能丰富知识面, 还 能促进学科融合; 另外, 部分项目充分利 用互联网传播信息的功能, 如在体育舞 蹈教材中, 不论是基本动作、高难动作还 是组合动作, 都有对应的二维码, 当读者 在大脑中无法构思该动作或想要正确学 习该动作的要点时, 即可扫描与动作对 应的二维码进行学习; 最后, 多种形式的
网络学习之后, 学生还能通过教师所上 传的测验、试卷等学习评估方式进行对 自己的学习成果的检验, 以对学习的进 度和深度等进行调整。

3. 3提升学生的学习积极性。李晓 文 ${ }^{[17]}$ 曾在研究中发现, “互联网+教学” 环境对教学过程、师生行为和师生互动 关系有着一定的促进作用。潘陈青 ${ }^{[18]}$ 认 为, 通过互联网能够实现体育用户从“被 动的受众” 到 “主动的用户” 的转变。线 上学习能从多方面提高学生的学习积极 性, 实现从 “要我学” 向 “我要学” 的发 展。如学生通过网络学习弥补自己的短 板、通过网络论坛为他人答疑、学习可自 主选择的兴趣课程等, 都能帮助学生增长 其学业自信。此外, 互联网作为一种教学 手段, 能使学生在课堂上与教师和其他学 生进行积极的互动, 促进彼此想法的交流 和资源的共享, 同时, 结合翻转课堂和混 合式教学等多种教学方式, 也能提升学生 自主学习和独立思考的能力, 与传统教学 的教学效果相比, 互联网教学更能促进学 生综合水平的全面发展。

\section{4 “互联网 + ” 背景下我国高}

\section{校体育课程的发展路径}

4. 1 合理利用现代科技, 推进教育信 息化。2018年教育部所颁发的《教育信 息化2.0 行动计划》中提到, “发挥技术 优势, 变革传统模式, 推进新技术与教育 教学的融合, 真正实现从融合应用阶段 迈入创新发展阶段, 不仅实现常态化应 
用, 更要达成全方位创新。” ${ }^{[19]}$ 现代科技 进入体育教育主要包含看两个方面, 一 是将其运用在体育课堂中, 灵活运用现 代科技设备如手机、平板等作为录像设 备, 心率测量器、跑台等作为测量设备, 电视、投影仪等作为视频资料播放设备; 二是将其运用在体育课程、学生体质健 康监测、网络教学资源等的管理当中。

4.2 明确学生成长目标, 激发学习主 动化。在线体育课程所强调的目标应与国 家的标准保持一致, 实现体育课程的最终 目标一一终身体育。在我国在线体育课程 的发展中, 应避免像美国在线课程安排中 出现的问题, 体育教师应从实际出发, 从 学生的成长目标出发, 合理运用现代科技 技术, 安排能满足学生身体素质发展需求 的课程, 切忌为了融合现代科技, 盲目使 用不适宜的技术。另外, 合理安排课程与 信息技术的结合能一定程度上促进学生 的学习动机, 使其更主动地参与线上的学 习, 可以通过结合新技术, 灵活使用多种 教学方法和手段, 提高学生学习的积极 性和线上与教师的互动性。

4. 3凝聚社会多方力量, 促进课程优 质化。通过阅读国外文献可以了解到, 美国大多数州对于线上教师进行了明确 的资格规定, 要求其至少具有州以上的 教师资格。另外, 美国也非常重视学校、 社区、家庭等社会多方力量的整合。 ${ }^{[20]}$ 值得注意的是, 学生体育素养的培养和 终生体育习惯的形成并非仅仅依靠学校 能够实现的, 因此在我国发展线上体育 教育时, 不仅需要对线上教师进行考核, 保证线上教学的高质量, 还应鼓励线上 线下混合式教学, 鼓励社区监督、家长参 与到学生的学习过程当中, 学生也应该 充分发挥其主观能动性, 多方凝聚才能 使得在线体育课程顺利开展。

\section{5 结语}

目前, 科学技术与教育行业的融合 发展是大势所趋, 体育课程中加入科技 力量也是形势所迫, 实时了解国内外体 育课程在互联网大数据背景下的发展前
沿, 将高科技产品、高科技手段、高科技 方法、高科技思维运用到体育的学习当 中能大大促进体育教育的发展。高校体 育课程的互联网教学能构建大数据、满 足学生个性化需要、提升学生的学习积 极性, 因而, 对我国高校体育课程与互联 网的融合发展提出以下建议: (1) 合理利 用现代科技, 推进教育信息化; (2) 明确 学生成长目标, 激发学习主动化; (3) 凝 聚社会多方力量, 促进课程优质化。

\section{[参考文献]}

[1]李兴平. “互联网+”背景下初中 体育教学变革的探究 [J]. 课程教育研 究,2020,(19):213.

[2]秦松,丁元江. “互联网+”促进体 育教学发展策略研究 [J]. 成才之 路,2020,(18):116-117.

[3]0nline-Physica]-Education[EB/ OL].[2018-05-12].http://homeschoolin g.about.com/od/physicaledlinks/p/0nlin e-Physical-Education.htm.

[4]STOVERD.No,rea17y:P.E.online[J] .Education Digest,2005,71(3):41.

[5]PICCIANO A,SEAMAN J.K-12 online learning:a survey of U.S.school district administrator[M].MA:The Sloan Consortium, 2007.

[6]National association for sport and physical education (2016) [EB/OL]. [2018-05-12].http://www.shapeamerica .org/advocacy/son/2016/upload/Shape-0 f-the-Nation-2016_web.pdf.

[7]刘珍,黄爱峰,王健, 等.美国在线 体育课程及其课程指南解析 [J]. 首都体 育学院学报,2019,31(03):243-247+254.

[8]MCNAMARA J,SWALM R, STEARNE D,et al.0nline weight training[J].Journa] of Strength and Conditioning Research, 2008,(22):1164.

[9]KOOIMANBJ,SHEEHANDP.Theeffic acyofexergamesforsocial relatedness in online physical education[J].Cogent Education,2015,2(1):4.
[10]DAUM D N, BUSCHNER C.The status of high school online physical education in the united states[J]. Journal of Teaching in Physical Education,2012,31(1):86.

[11]BRIAN J K,DWAYNE P S. The efficacy of exergames for social relatedness in online physical education[J].Cogent Education,2015,2(1):4.

[12]刘红艳.基于互联网＋教育下体 育课程改革发展创新研究——评《高校 体育教育创新理念与实践教学研究》[J]. 林产工业,2020,57(03):121。

[13]林岗.缺失与重建: “互联网+” 时代成人体育教育发展探析[J].成人教 育,2020,40(06):72-75.

[14]尹忠根,杨宗友,李采丰. 基于 “互联网+”的大学体育课内外健康数 据一体化实践研究 [J]. 西南师范大学学 报(自然科学版),2020,45(04):108-114.

[15]赵彩铅, 赵歆。“互联网+教育” 视域下大学武术教学改革研究 [J].体育 文化导刊,2018,(05):1 19-123.

[16]姜玉红.移动互联网场景下的高 校体育教学改革研究[J].西南师范大学学 报(自然科学版),2018,43(12):178-184.

[17]李晓文,叶伟剑,章秋红. “互联网+ 教学”环境下师生互动行为指数模型研究 [J].高等工程教育研究,2020,(03):157-162.

[18]潘陈青,付晓静.从受众到用户: “互联网+”时代体育传播转型路径初 探一一基于传播游戏理论 [J]. 体育科 学,2018,38(05):17-24.

[19]教育部、教育部关于印发《教育 信息化2.0行动计划》的通知 $[A]$.2018.

[20]郑燕林.美国 K-12网络教育 发展的特征及启示 [J]. 中国电化教 育,2014,(3):42.

作者简介：

袁雨馨(1998--), 女, 汉族, 四川成都 人, 北京体育大学硕士在读研究生, 体育 教育训练学专业。 